\title{
8. Triage due to road accidents in Bulgaria - a questionnaire survey of self-assessment of readiness of emergency medical care center in Blagoevgrad region
}

\author{
Diana A. Dimitrova, PhD' \\ ${ }^{1}$ Department of Preventive Medicine, FPH, MU-Sofia, Sofia, Bulgaria
}

\begin{abstract}
Medical triage (MT) is an important practical tool in the healing process within the scope of Emergency medicine specialty in the country. The main field of application and implementation of MT mostly refers to the teams of the emergency medical care center (EMCC). The experience in this direction is significant for the terrestrial medical transport teams in the country. The E79 main road and the Struma highway are part of the infrastructure in Blagoevgrad region which is served by 10 branches of the EMCC-Blagoevgrad. The knowledge and skills of the teams at EMCC-Blagoevgrad to provide medical triage to the victims in the event of road accidents (RA) is an essential element of the team preparation, due to the high frequency of serious car accidents in southwestern Bulgaria. (1-6)
\end{abstract}

Purpose. The aim of the study is to examine and analyze the readiness of medical teams of EMCC and Self-assessment of readiness to provide medical triage in case of mass trauma due to road accident.

Materials and methods $A$ questionnaire survey with the teams of EMCC-Blagoevgrad region was conducted - 300 respondents. (Fig.1.) On the other hand available (EMCC and GDFSCP) databases are researched and analyzed as well for 10-year period.

Results and discussions. Over 10 years, more than 5,000 people died in the RA, and around 9,000 people were injured every year in Bulgaria. (Table 1.) $(5,6)$ For the period January - March 2019, in the RA more than 100 people die, and 1500 injured. (5) The survey shows that $60 \%$ are seriously injured. Of these by the nature of trauma: with immediate vital disturbances group T1 (20-40\%); group T2 (20\%); T3 (40\%); T4 (20\%). (Fig.2.) Specialists with Emergency Medicine specialty in EMCC is only about $1 \%$ of the staff. The importance of MT is reported by about $60 \%$ of staff, but just $5 \%$ say they know how. More than $\mathbf{8 0} \%$ say there should be specific MT training. (1)The development of a postgraduate program of training for physicians, medical assistants and nurses working at EMCC-Blagoevgrad and the introduction of this program in the form of compulsory regular annual training is an important stage for maintaining a constant high level of readiness of the medical staff of EMCC-Blagoevgrad for the medical triage of victims due to road accidents. This program can also serve as an element of a larger risk reduction program to reduce the risk of fatal injuries in road accidents of any type on the territory of the country as a whole. On the other hand, this program can be used as the basis for implantation it in other regions with a high concentration of road accidents, and across the country for enhancing the overall level of competence of the medical staff in the EMCC system in Bulgaria.

Key words: Medical triage, mass injuries, traffic accidents, emergency medical care center, Bulgaria

Sources:

1.Dimitrova D., Medical provision of population during earthquakes - readiness of Emergency medical care center in Blagoevgrad region., MU-Sofia, 2015 - PhD thesis

2.D. Dimitrova, Road transport accidents in the focus of public health in Bulgaria, Trakia Journal, TJS, 2018; Vol.16, suppl.1, pp168-170

3. D. Dimitrova, Challenges in emergency medical care center in Bulgaria in case of mass

traumatism during disaster situations - epidemiological survey, September 2018 - Resuscitation, Volume 130 , Supplement 1 (2018), 09/2018; 130:e139.

DOI:10.1016/j.resuscitation.2018.07.299

4. Dimitrova D., System of emergency medical care center in Bulgaria - analyses of the current status and future development trends, in: Guideline of preventive medicine, Pub. Science and art, Sofia., 2017

5.Evidence base data by GDFSCP, https://www.mvr.bg/dokkpbdp 6.Evidence base data by NSI, http://www.nsi.bg/bg/content/14772
Table 1. Deaths and injuries for the period 2009 to 2018 due to road accidents in Bulgaria and Blagoevgrad region (Source GD"FSCP" - Mol)

\begin{tabular}{|c|c|c|c|c|c|c|}
\hline \multicolumn{3}{|c|}{$\begin{array}{c}\text { TOTAL } \\
\text { in Blagoevgrad region }\end{array}$} & \multirow[t]{2}{*}{ Year } & \multicolumn{3}{|c|}{$\begin{array}{c}\text { TOTAL } \\
\text { in Bulgaria }\end{array}$} \\
\hline RA & Died & Injured & & RA & Died & Injured \\
\hline & 18 & 377 & 2018 & 6690 & 611 & 8471 \\
\hline 288 & 26 & 351 & 2017 & 6880 & 682 & 8680 \\
\hline 364 & 39 & 433 & 2016 & 7404 & 708 & 9374 \\
\hline 303 & 34 & 380 & 2015 & 7226 & 708 & 8973 \\
\hline 300 & 27 & 394 & 2014 & 7015 & 660 & 8640 \\
\hline 661 & 7 & 239 & 2013 & 7016 & 601 & 8776 \\
\hline 1297 & 34 & 363 & 2012 & 6717 & 601 & 8193 \\
\hline 348 & 27 & 442 & 2011 & 6638 & 657 & 8303 \\
\hline 335 & 45 & 432 & 2010 & 6610 & 775 & 8080 \\
\hline 333 & 26 & 418 & 2009 & 7068 & 901 & 8674 \\
\hline
\end{tabular}

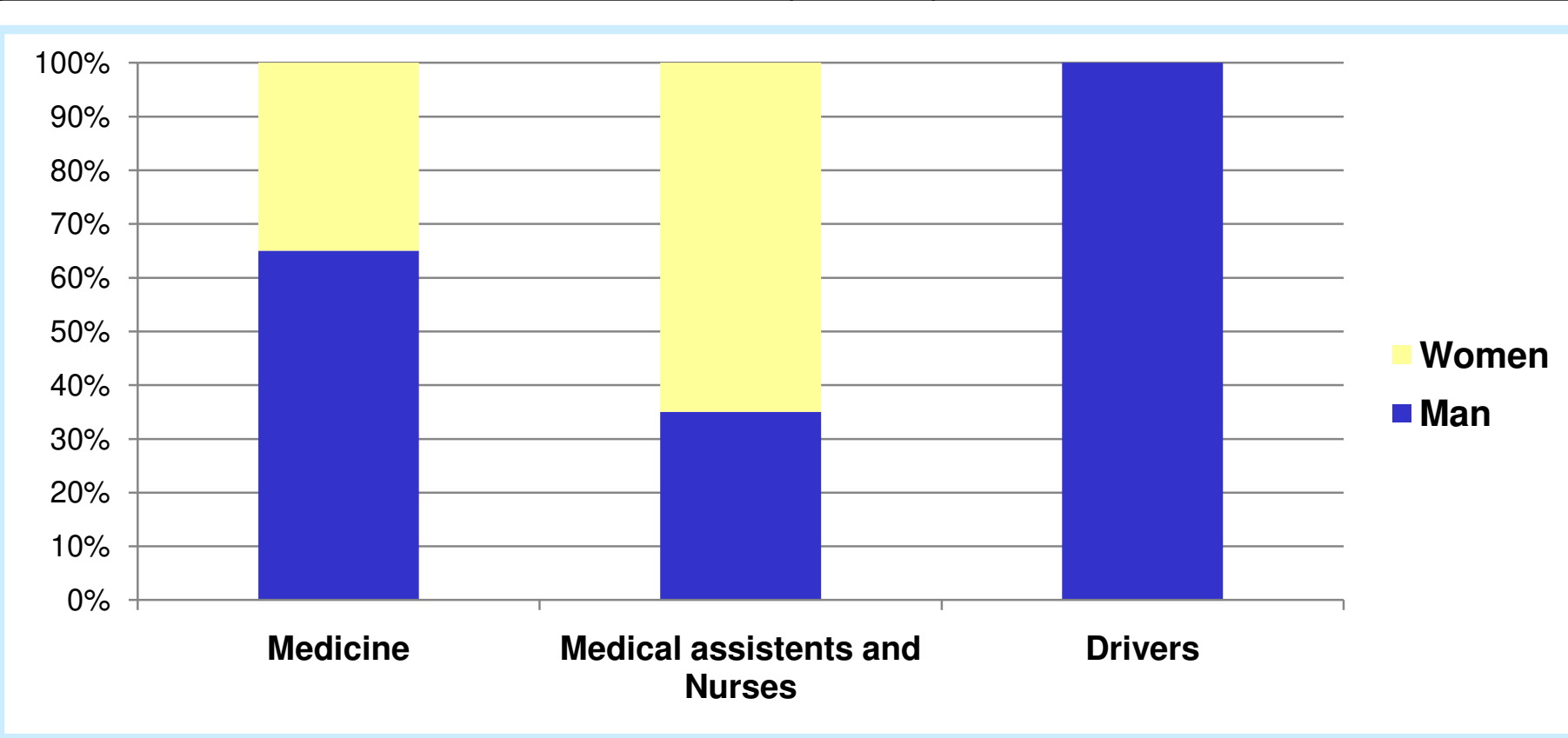

Fig.1. Two-dimensional gender distribution and professional status at EMCC for all affiliates in Blagoevgrad region (Bulgaria). Relative share (\%).

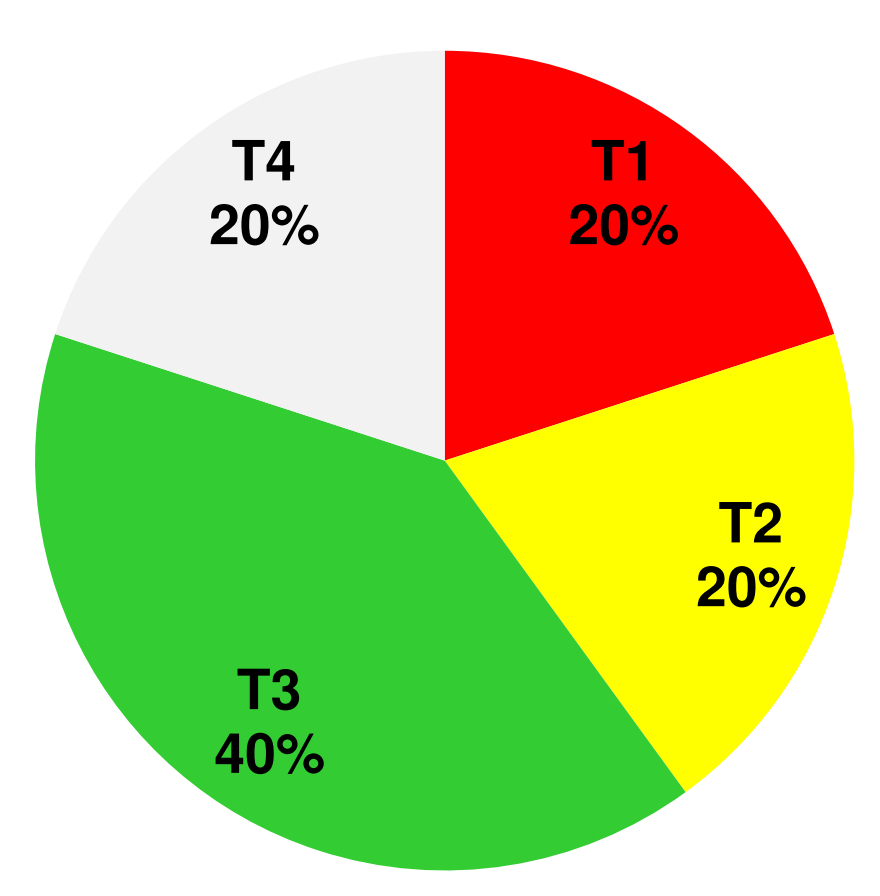

Fig.2. T1 - life-threatening condition damage with a high probability of death if you do not take immediate interventions (shock; burning over 20\%); T2 - severe injuries (need urgent medical assistance, an unstable /potentially unstable emergency patient); T3 - moderate damage (a stable emergency patient); T4 - agonizing, lifeincompatible injuries (Brain death syndrome, $90 \%$ burning)

Conclusions. There is a significant number of victims of road accidents in the country. The distribution of MT in sub-types specifies it. The need for MT implementation by EMCC teams is available. These teams are the main contractors of Medical Triage and need specialized training about MT application. This study gives the idea of expanding and reaching a higher level of skills and knowledge by preparing a comprehensive training program on conducting medical triage in road accident victims.

European Resuscitation Council Congress, 19-21 September 2019, Ljubljana Copyright $\odot 2019$ Author: D. Dimitrova 